\title{
20th Conference on Power System Engineering
}

\author{
Lukas Richter ${ }^{1 *}$, Martin Pelikan ${ }^{1}$, Michal Volf ${ }^{1}$ and Michaela Vackova ${ }^{1}$ \\ ${ }^{1}$ University of West Bohemia in Pilsen, Univerzitni 22, 30614 Pilsen, Czech Republic.
}

\begin{abstract}
The Conference on Power System Engineering has a long-term tradition. It is an annual meeting of professors and experts from departments and universities where power system engineering is taught. The $20^{\text {th }}$ year of this event was held in Pilsen (Czech Republic) between 7th and 9th September 2021 and was hosted by Department of Power System Engineering of Faculty of Mechanical Engineering, University of West Bohemia in Pilsen.
\end{abstract}

\section{Preface}

There were 74 delegates from academic and industrial field who came from the Czech Republic, the Slovak Republic, Germany, Hungary, Poland, Ukraine and Russia. The conference was launched by the rector of the University of West Bohemia. The organizers received 35 contributions. 34 contributions have gone through a professional review for the publication. All presentations brought contributions to the fields of equipment for classic and nuclear power plants including their operation, fluid mechanics and flow simulations, thermodynamics, heat transfer, diagnostics of power machines and equipment etc.

The social evening with a programme gave the delegates an opportunity to meet their colleagues, share and discuss their experience and results of their research projects in less formal environment. The participants could also visit the world-famous brewery Pilsner Urquell. The programme of the conference included also a student section, in which especially Ph.D. students have an opportunity to present their contributions or posters.

The conference was financially supported by a Visegrad grant. The main goal of the grant is to build an international network of scientists and experts in the V4 region with the focus on energy savings, efficiency and reliability increase in various industrial processes, development and implementation of emission-free technologies. At a time of transformation of the energy industry caused by the ever-increasing demand not only for electricity, but also for other forms of energy, decarbonization and the reduction of fossil fuel reserves, it is necessary to work especially in academia to develop new technologies and methods to implement energy savings. The issue of energy savings is currently addressed to some extent by all the grant partners. However, since each workplace has a certain area of focus, the results of such research have limited scope. Only the international cooperation of these workplaces offers a comprehensive solution, because only then is it possible to communicate experience and knowledge in specific areas in order to harmonize the activities of the individual workplaces.

\footnotetext{
* Corresponding editor: richterl@kke.zcu.cz
} 


\section{supported by \\ Visegrad Fund}

Fig. 1. Visegrad fund - Project ID/Title: 22110166/ Conference on Power System Engineering 2021.

The conference organizers would like to thank all industrial and academic partners of the conference for their financial support. The Institute of Thermomechanics of the Academy of Sciences of the Czech Republic contributed financially to the organization of the conference within the framework of the Strategy 21. Other significant financial support came from Doosan Škoda Power, AFRY, NUM solution, ATMOS Chrast, Helago, Techsoft Engineering, TechSim Engineering and Czech Society for Mechanics.

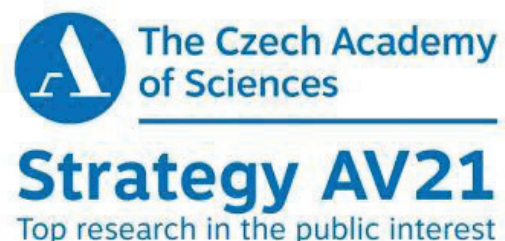

Top research in the public interest

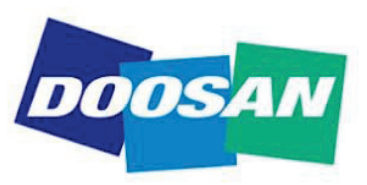

Doosan Škoda Power

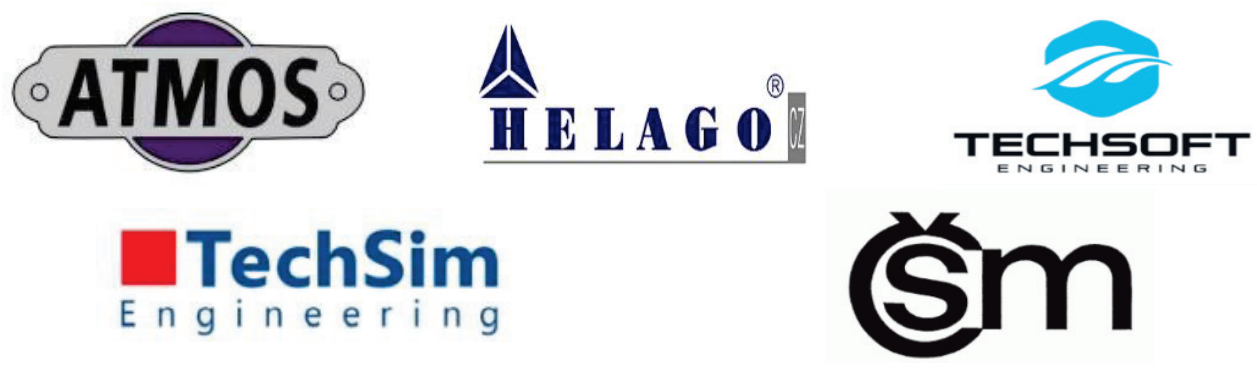

Fig. 2. Logos of sponsoring organizations. 